\title{
Men at Middle Age: Developmental Transitions
}

\author{
$B y$ LOIS M. TAMIR
}

\begin{abstract}
The transition to middle age can simultaneously be a time of peak performance and a time of psychological setbacks in the lives of men. In the process of preparing for the second half of life, the man must deal with health issues, his imminent death, self-assessment, his sex role, and his responsibilities to future generations. The working through of these tasks is reflected in the work, family, and social lives of men at this stage. At the work place the man must either accept his failure to achieve his long-term goals or he must decide if having reached his goals has been worth the effort. Many men, as a result, disengage from the work place as their major source of personal fulfillment. On the other hand, interpersonal relations begin to come to prominence at the middle-age transition. The marital bond and sense of social connectedness felt by the individual become more integrally related to personal wellbeing at this time. The policy makers and corporate enterprises so entwined in the lives and well-being of men need to take into account these issues of middle age in order to ease the transition and to avoid the necessity of making a painful choice between occupational and interpersonal fulfillment.
\end{abstract}

Lois $M$. Tamir received her B.A. (summa cum laude) in sociology from SUNY at Stony Brook in 1974, and her Ph.D. in developmental psychology from the University of Michigan in 1980. She worked from 1978-80 at the University of Michigan's Institute for Social Research as a research fellow. Currently, she is clinical assistant professor of psychiatry at the University of Texas Health Science Center at Dallas, and is adjunct assistant professor of psychology and human development at the University of Texas at Dallas. She has published research in the areas of interpersonal communication, the family life cycle, middle age, and old age from the perspective of life span developmental psychology.

NOTE: The author would like to thank Beverly Bonnheim for her helpful comments on the article. 
$\mathrm{M}$ OST of us, regardless of education or profession, would probably agree that the middle-aged adult is at the apex of life. ${ }^{1}$ The middle-aged adult generally operates at his optimum level as he interacts with others, is at his peak earning capacity, and executes projects at his greatest level of efficiency. Why, then, has so much attention been paid to the so-called midlife crisis, a term now well ingrained in our vocabularies? I think an answer lies in the fact that the peak of life often stimulates a period of selfassessment. One cannot remain at a peak forever, but must prepare to face a downhill journey, or perhaps a walk along a plateau. This article examines the tasks confronted by men at middle age by virtue of this psychological state of affairs, tasks that are part of a natural developmental progression. It also takes a look at how these tasks are handled in three central spheres of life: work, family, and social relationships.

\section{TASKS OF TRANSITION}

The period in which this developmental dilemma comes to the forefront of the man's life appears to be the time in which he makes his transition to middle-aged status. For most men this transition occurs when they are in their forties.

1. See, for example, J. E. Birren, "Toward an Experimental Psychology of Aging," American Psychologist, 25:124-35 (1970); L. B. Bourque and K. W. Back, "The Middle Years Seen through the Life Graph," Sociological Symposium, 3:19-29 (Fall 1969); P. Cameron, "The Generation Gap: Which Generation is Believed Powerful versus Generational Members' Self-Appraisals of Power," Developmental Psychology, 3:403-4 (May 1970); and B. L. Neugarten, "The Awareness of Middle Age," in Middle Age and Aging, ed. B. L. Neugarten (Chicago: University of Chicago Press, 1968). pp.93-98.
Although scholars of life-span development are often loath to pinpoint even approximate ages for developmental phenomena, the literature suggests that men in their 40s experience significant personal transition, crisis, or simply a heightened awareness of themselves. ${ }^{2}, 3$ On a more dramatic level, clinical studies reveal that this population has a significant increase in mental health problems, including depression, alcoholism, and suicide. ${ }^{4}$ Whether dramatic or subtle, however, most studies that range over the span of adulthood display something atypical among middle-aged men, whether a blip in a curve, a deviation from the norm, or a qualitative transformation.

The problems a man confronts as he enters middle age are many and

2. See, for example, C. G. Jung, Modern Man in Search of a Soul (New York: Harcourt Brace Jovanovich, 1933), who talks about the "afternoon of life" at age 40; B. Fried, The Middle-Age Crisis (New York: Harper \& Row, 1976), who calls the 40s “middlescence"; and other researchers such as D. J. Levinson, The Seasons of a Man's Life (New York: Knopf, 1978); and G. E. Vaillant, Adaptation to Life (Boston: Little, Brown, 1977), as well as E. Frenkel-Brunswik, "Adjustments and Reorientation in the Course of the Life Span," in Middle Age and Aging, ed. Neugarten, pp. 77-84, who, 50 years ago, talked about personality change among men in their $40 \mathrm{~s}$.

3. Note should be taken, however, that the higher the socioeconomic class, the later the onset of middle-age and old-age transitions.

4. See in Modern Perspectives in thePsychiatry of Middle Age, ed. J. G. Howells (New York: Brunner/Mazel, 1981); J. H. Boyd and M. M. Wasserman, "The Epidemiology of Psychiatric Disorders of Middle Age: Depression, Alcoholism, and Suicide," pp. 201-21; F. O. Henker, "Male Climacteric," pp. 304-12; and P. M. Mirkin and R. E. Meyer, "Alcoholism in Middle Age," pp. 251-65. Also see R. L. Meile, "Age and Sex Differences in Psychiatric Treatment," Sociological Symposium, 3:107-13 (Fall 1969). 
varied, overt and covert. Overt changes include his children becoming teenagers and often leaving home soon after, his parents aging and possibly dying, and his job or profession becoming more limited in future options. ${ }^{5}$ Covertly, it seems that lack of change may depress the man at middle age. ${ }^{6}$ No longer is he the object of attention at momentous events, such as weddings, births, first homes, or outstanding promotions.

This peak of life is also plagued with insults to one's sense of wellbeing. My own research, which has examined the transition to middle age based on a recent national survey, ${ }^{7}$ has documented this slump in a man's sense of well-being during his forties. Of interest is the fact that educational background seems an important criterion as to how a man deals with his move to middle age. College-educated men were more depressed, displayed more symptoms of psychological immobilization, had more drinking problems, and more readily turned to drugs to relieve nervous tension, although,

5. See, for example, D. C. Borland, "Research on Middle Age: An Assessment," The Gerontologist, 18:379-86 (Aug. 1978); S. D. Rosenberg and M. P. Farrell, "Identity and Crisis in Middle Aged Men," International Journal of Aging and Human Development, 7(2):153-70 (1976).

6. J. M. Bardwick, "Middle Age and a Sense of Future," Merrill-Palmer Quarterly, 24(2):129-38 (1978).

7. L. M. Tamir, Men in Their Forties. The Transition to Middle Age (New York: Springer, 1982). The total sample from this national survey study included 551 men aged 25-69 years who were married and had children, 133 of whom were in the age range of 40-49 years. For a full report concerning the national survey itself see: J. Veroff, E. Douvan, and R. A. Kulka, The Inner American, or J. Veroff, R. A. Kulka, and E. Douvan, Mental Health in America (New York: Basic Books, 1981). surprisingly, their self-esteem remained intact. In contrast, men with a high school education or less were more likely to plummet only in the area of self-esteem. It is important to note that all these symptoms were limited to a very small age range, namely, men aged $45-49$, a startling result considering that they were compared with men ranging the entire lifespan.

In light of the research to date, it appears that there is an air of discontent seeping into the lives of men at this time, but a discontent that need not be indicative of a fullblown crisis. Instead, it is likely that a period of introspection has begun and has taken a different form in accord with educational background.

This sense of introspection appears to be firmly anchored in the psychological tasks specific to middle age, and in particular to men at this time. These tasks fall under five major headings: health, mortality, self-assessment, sex role, and generativity.

\section{Health}

Middle-aged men do not suddenly experience ill health, but the symptoms of physical decline, which had begun perhaps a decade earlier, begin to reveal themselves. The body becomes less reliable and predictable as arteriosclerosis develops, fat deposits appear, arthritis threatens, and testosterone production diminishes, to name just a few physical alterations. ${ }^{8}$ Even if these symptoms are minor, it is at this point that men begin to react more emotionally to physical changes. 304-12.

8. Henker, "Male Climacteric," pp 
Accordingly, their wives are known to monitor their husbands' bodies more closely than their own. ${ }^{9}$

\section{Mortality}

Highly related to the issue of health is the issue of mortality, for at middle age the man becomes painfully aware that he has lived perhaps half his lifetime. Bernice Neugarten best describes this phenomenon as a switch in focus from "time since birth" to "time left to live."10 Elliott Jaques ${ }^{11}$ has written most explicitly of the middle-aged man's coming to grips with his mortality, and he believes that this struggle defines middle age. Mortality, however, is not the only issue of middle age-the tasks of selfassessment, sex roles, and generativity are also powerful stimuli to personal change at the midlife transition. Nevertheless, these three tasks are integrally related to the tasks of accepting mortality, since that in itself can force the individual to confront internal psychological issues. The middle-aged man must make peace with himself in order to comfortably survive the remaining future.

\section{Self-assessment}

Self-assessment, in contrast to mortality, is possibly the most integral task of middle age. It involves a process of examining one's individual life and one's place in the wider

9. B. L. Neugarten and N. Datan, "The Middle Years," in American Handbook of Psychiatry, ed. S. Arieti (New York: Basic Books, 1974), pp. 592-608.

10. Neugarten, "The Awareness of Middle Age," pp. 93-98.

11. E. Jaques, "Death and the Mid-Life Crisis," International Journal of Psychoanalysis, 46:502-14 (1965). social environment. ${ }^{12}$ Selfassessment also involves coming to terms with life's contradictions. During youth and young adulthood the individual, working toward specific life goals, typically relies on principles outlined in black and white. By middle age, however, the wisdom of experience allows the individual to recognize shades of gray and the multiple factors that sway the decision-making process and goal attainment. It is at this point that contradictions are recognized, not with outrage, but with acceptance, and according to the research by Daniel Levinson, life's polarities are reintegrated. ${ }^{13}$ The psychologist Klaus Riegel ${ }^{14}$ has described this stage as the highest level of cognitive functioning: dialectical thought.

Sex role

One of the great polarities is the masculine/feminine dichotomy. Much research has documented the reintegration of masculine and feminine traits at middle age. ${ }^{15}$

12. Neugarten, "The Awareness of Middle Age," labels this process "interiority," pp. 93-98.

13. Levinson, in The Seasons of a Man's Life, identifies the major polar concepts as young/old, destruction/creation, attachment/ separateness, and masculine/feminine.

14. K. F. Riegel, "Dialectic Operations: The Final Period of Cognitive Development," Human Development, 16:346-70 (1973).

15. See, for example, D. Gutmann, "Parenthood: A Key to the Comparative Study of the Life Cycle," in Life-Span Developmental Psychology: Normative Life Crisis, (New York: Academic Press, 1975); pp. 167-84. Jung, Modern Man in search of a Soul: Levinson, The Seasons of a Man's Life; B. L. Neugarten and D. L. Gutmann, "Age-Sex Roles and Personality in Middle Age: A Thematic Apperception Study," in Middle Age and Aging, pp. 68-71. 
While women become more assertive and independent, men become more sensitive and nurturant. There are many possible reasons for this reintegration, in addition to the internal reworking of polarities just discussed. It may be that at this point the man takes stock of all the sacrifices he has had to make in order to maintain a strong masculine image, including enduring the stress of his job, and sacrifices in his interpersonal life and his relationships with his children. He may attempt to remedy the situation by developing a more well-rounded personality. It has been suggested, in fact, that all personality traits either previously submerged or not allowed to develop now begin to make their appearance in the transition to middle age..$^{16}$

\section{Generativity}

The final psychological task of middle age involves taking responsibility for future generations, be they one's own offspring or protégés, or a less tangible, more abstract group of younger adults. This means offering guidance and developing a personal legacy that will leave an imprint upon the future cohorts. Erik Erikson ${ }^{17}$ writes most cogently of this task, labeling it a crisis of "generativity versus stagnation or self-absorption." If the adult in transition can successfully work through the tasks of middle age, he is free to

16. Preliminary research cited in $S$. Cytrynbaum et al., "Midlife Development: A Personality and Social Systems Perspective," in Aging in the 1980's, ed. L. W. Poon (Washington, DC: APA, 1980), pp. 463-74.

17. E. Erikson, Childhood and Society (New York: Norton, 1950); also, "Adulthood and World Views" (Unpublished paper prepared for Conference on Love and Work in Adulthood, American Academy of Arts and Sciences, Palo Alto, CA, May 1977). contribute to others. If not, he will tend to stagnate, being more absorbed in himself than in what he can do for others.

\section{WORK, FAMILY, AND \\ SOCIAL RELATIONSHIPS}

Given these basic psychological tasks faced by men in the transition to middle age, it is useful to examine their repercussions at work, in the family, and with social relationships -three spheres of living upon which personal quality of life is highly contingent.

\section{Work}

Perhaps no other role is more integral to the identity of the male than the work role. Not only is work a source of income and sustenance for the man and his family but it is also the clock by which the man assesses life's achievements as to whether they are on time, successfully early, disappointingly late, or woefully not forthcoming. And it is in the work environment that the man becomes most aware when he has reached his peak: most typically at middle age.

Usually by middle age the male worker, be he blue collar, white collar, or professional, has reached a plateau. At best, a lateral shift in occupational position will occur. ${ }^{18}$ This tangible work situation in itself may stimulate self-assessment at middle age, for the man must psychologically maneuver himself out of a difficult no-win situation: if he

18. A. J. Jaffe, "The Middle Years: Neither Too Young Nor Too Old," Special Issue of Industrial Gerontology, Washington, DC: National Council on Aging, 1971, writes most thoroughly about this process. It should also be noted that blue-collar workers peak earlier than white collar. 
has not achieved the success he has worked toward all his life, he will be terribly disappointed; if he has achieved what he has set out to do, he must assess whether it is actually all that wonderful, and where he should go from that point.

Research on how middle-aged men deal with this situation is mixed. While some researchers imply a sense of resignation from the work environment and a distancing from the cutthroat race for promotion, ${ }^{19}$ others suggest a period of overinvolvement with work in terms of time and quantity. ${ }^{20}$ Part of this overinvolvement may actually be because retirement is nearing and financial security becomes a key to future survival, in particular for the lower-middle-and working-class populations. ${ }^{21}$ The national survey research referred to earlier indicates the former pattern of resignation during one's $40 \mathrm{~s}$. As in the results described earlier, the patterns differ somewhat for college- and noncollege-educated men. In assessing the relationship between work and well-being, it was found that only during the 40 s did work bear no relationship to wellbeing. Men at this stage could be thriving on the job, yet dissatisfied with life or, on the opposite end, unhappy with the work situation, but generally satisfied with their

19. See, for example, J. A. Clausen, "Glimpses Into the Social World of Middle Age," International Journal of Aging and Human Development, 7:99-106 (1976).

20. See, for example, J. M. Bardwick, "Middle Age and a Sense of Future;" and C. L. Cooper, "Middle-Aged Men and the Pressures of Work," pp.90-102 in Modern Perspectives in the Psychiatry of Middle Age, ed. J. G. Howells (New York: Brunner/Mazel, 1981).

21. M. F. Lowenthal, M. Thurher, and D. Chiriboga, Four Stages of Life (San Francisco: Jossey-Bass, 1975). lives. At all other ages men's work satisfaction was highly and significantly related to their sense of wellbeing. This surprising result appears to be a key indicator of some sort of disengagement from the work environment by middle-aged men, for work had little bearing upon their psychological well-being at this precarious time in life, especially in comparison with their earlier years.

These survey results are far from isolated. The Wall Street Journal ${ }^{22}$ recently reported that managers from AT\&T who were followed for 20 years displayed a significant drop in desire for advancement when they reached their $40 \mathrm{~s}$. No longer was their happiness correlated with work success.

Of interest with regard to the work environment are concerns with interpersonal relationships on the job. For colleged-educated men, the national survey revealed that only at the middle-age transition, the $40 \mathrm{~s}$, was the opportunity to talk with others at work highly and significantly related to job satisfaction when compared with older and younger men. If, in fact, there is a degree of job disengagement at this time, the interpersonal aspect of work is considered an important feature of work satisfaction. Perhaps the interpersonal side of work involves the emergence of the mentor-protégé relationship that Daniel Levinson found in his research of men at middle age. Becoming a mentor certainly provides an excellent vehicle for accomplishing the task of generativity so crucial to a successful middleage transition.

22. Wall Street Journal, Labor Letter section, Mar. 16, 1982. 


\section{Family}

In light of the difficult psychological work confronted by middleaged men, there are bound to be repercussions at home and in relationships with wives and children. Other family members, too, are likely to be in transition. Mothers are no longer nurturing small children and possibly are investigating new opportunities outside the home. Children are now teenagers seeking independence and freedom from parents. This situation makes for a complex interplay of interpersonal needs that are fulfilled or surpressed in the multiple relationships of family life.

It appears that during this time of transition, new terms are established for the relationship between husband and wife. Middle-aged spouses must shift their focus from a mutual concern with child care to a mutual concern with their own relationship, from roles of fathermother to roles of husband-wife. This shift of focus, of course, can either arouse interpersonal tension, since members of a strained relationship do not have their children as an outlet to divert attention from themselves, or it can solidify a relationship, allowing husband and wife further time to explore, rediscover, and enjoy one another. Indeed, Marjorie Lowenthal's research has indicated a more intense focus upon the man's role as husband than as father during the middle years.

It is not surprising to read in the clinical literature ${ }^{23}$ that marriages

23. See, for example, H. J. Friedman, "The Divorced in Middle Age," in Modern Perspectives in the Psychiatry of Middle Age, ed. Howells, pp. 103-15. that dissolve in middle age often do so as a result of underlying interpersonal problems that have existed from the beginning of the marriage. The presence of children can deflect these problems for quite a while, only to have the problems reemerge when the nest is emptied and husband and wife must face one another as separate persons once again.

The national survey study also reveals a striking pattern of results concerning the family lives of men in their $40 \mathrm{~s}$. Only men in their $40 \mathrm{~s}$ viewed their adequacy as a father and adequacy as a husband as separate. Unlike men younger or older, this middle-aged group felt a psychological split between the two roles, perhaps because men at this age tend more to introspectively assess their lifetime roles. In turn, this split brings with it an emphasis, or rather reemphasis, upon the marital role.

This shift to the ever-increasing prominence of the marital role is displayed in the national study most clearly for men with a college education. Compared with older and younger men, the marital happiness of men in the $40 \mathrm{~s}$ was most highly and significantly related to their psychological well-being. General happiness, life satisfaction, selfesteem and the presence or absence of depression and alcoholism were more strongly related to marital happiness in the 40s than at any other age. Similarly, the AT\&T study revealed that managers began to replace the primacy of work with the primacy of family when they reached their $40 \mathrm{~s}$.

The finding that there is a strong interdependence between marital contentment and a sense of wellbeing is of particular interest in light of the fact that, for men in their 
$40 \mathrm{~s}$, a sense of well-being is no longer contingent upon the work place. Apparently, for the middle-aged man, well-being takes an interpersonal turn, and he becomes more firmly embedded in his role as husband than in his occupational role, no matter how prestigious the latter.

\section{Social relationships}

The final major sphere likely to have an impact upon the quality of life at middle age is that of social relationships. Little is known about the social relationships of middleaged men, or even about the social relationships of men at any age. Most psychological researchers simply concede that women maintain more intimate friendships with one another than do men. How men's friendships change through the life span is also unknown. Friendships can be especially important during times of stress. It is an area of living that merits more intensive investigation, especially with regard to transitional periods within the adult life span.

The little work done to date concerning the social relationships of men at middle age is highly contradictory. While some research indicates a renewed interest in friends and community, ${ }^{24}$ other research indicates a lull in friendship relations and a shallowness of social ties at this time. ${ }^{25}$ Perhaps this mixed set of results is because men at middle age represent a mixed set of individ-

24. For example, R. L. Gould, "The Phases of Adult Life: A Study in Developmental Psychology," American Journal of Psychiatry, 129:521-31 (Nov. 1972); and A. Campbell, P. E. Converse, and W. L. Rodgers, The Quality of American Life (New York: Russell Sage, 1976).

25. For example, M. F. Lowenthal et al., Four Stages of Life. uals, some more socially oriented, some more withdrawn. Additionally, it is possible that many of the social relationships of men at this time are highly ambivalent. During a period of self-assessment comparisons of self with others can be discouraging and a blow to self-esteem, thus dampening what could otherwise be cohesive, supportive relationships with others.

A striking pattern of results concerning the social relationships of men in their 40s has emerged from the national survey study. The selfesteem of noncollege-educated men, presumed to be the more workingclass segment of the population at large, seemed more highly related to their sense of social connectedness during their forties. Social connectedness includes a sense of feeling cared for, needed, and liked by others. Only at this transitional period in life does social connectedness relate so directly and strongly to self-esteem, a fragile personal characteristic at this time.

The social side of life seems to be a major contributor to a man's sense of well-being when he reaches middle age. Researchers of middle age ${ }^{26}$ have shown an enhanced statistical relationship between social fulfillment and stress: those most socially active are least stressed; those most isolated are more subject to stress. Similarly, the men at middle age who feel distant from others are low in self-esteem. Men whose social connections are thriving maintain greater self-esteem.

\section{The trade-off at transition}

The findings relayed in this article fit together like puzzle pieces to

26. M. F. Lowenthal and L. Weiss, "Intimacy and Crises in Adulthood," The Counseling Psychologist, 6(1):10-15 (1976). 
form a clear and integrated pattern of the lives of men in transition to middle age. Foremost is the fact that men at this time are in the midst of reworking their lives. Well-being is altered as lives are evaluated at conscious and subconscious levels.

Work, family, and social relationships appear to be reshuffled in the process of transition. The trade-off is one between occupation and people, between objective accomplishment and interpersonal emotion. The work place is no longer as emotionally central, no matter how hard-working the man in his $40 \mathrm{~s}$ appears. Instead it is the social side of work that sparks the interest of the middle-aged man, who perhaps is nurturing a protégé, or delegating responsibilities to others in the most efficient yet sensitive manner.

Differences emerge along educational lines in relation to the types of close ties men in their 40 s hold with others. The well-educated man appears more reliant upon his wife than are men of more working-class backgrounds, to whom other interpersonal ties become more central. Although these interpersonal ties are not as defined as the marital tie, the marriage may very well be an integral component of a more amorphous sense of social connectedness. Further research is needed to clarify this speculation, for workingclass men in particular have difficulty discussing personal issues. $^{27}$ The point remains, however, that nonmonetary social security holds the key to happiness at middle age for men of all levels of income and class.

\section{POLICY IMPLICATIONS}

The issues pertinent to the middle-age transition of men suggest a

27. L. B. Rubin, Worlds of Pain (New York: Basic Books, 1976). number of recommendations to improve the quality of life for adults of both sexes, for a more wellbalanced life for men brings with it a more well-balanced set of options for women as well. Policy makers, businesses, and counseling services would do well to promote a psychological sense of balance for men. This can be achieved by means of an educated awareness of the transitional issues of middle age: namely, the individual's reassessment and reintegration of work, family, and social roles.

Reassessment appears inevitably midway through life, simply because the individual must derive a satisfactory set of plans for the second half of life in light of the successes and failures reviewed from the first half. Just as much time has passed as there is time left to live. The pain of reassessment can be eased, however, if men are encouraged early on, that is, from their childhood years, to live more wellrounded and integrated lives.

The stress upon work, often to the exclusion of sufficient emotional investments in family relationships, needs to be modulated. Work offers the individual a tremendous source of personal accomplishment and financial security. On the other hand, over-investment in work can deplete the individual's life of a sustaining and rewarding series of interpersonal relationships with family and significant friends. It is important that men not allow their work to be all-consuming, lest they find themselves confused and disengaged when reaching the midpoint in life and have little or no emotional and social relationships.

Perhaps the most painful emotion of the middle-age transition is regret. Regrets, however, can be avoided if the individual has taken opportunities to fulfill himself in 
cognitive, physical, and interpersonal realms. Ideally, he must derive equal enjoyment from work and family, as well as from other enriching activities throughout his adulthood years. Middle age, as a stage in life where polarities and contradictory activities are contrasted, compared, and accepted, can be much more fulfilling if the individual need not sway from one extreme to the other-from labor to love, from macho to maternal, from youthful to aged, and vice versa. A well-modulated life can enable the man in transition to middle age to reap the rewards of his age, his experience, and his insights in beneficial ways.
This is not to say that crisis is bad. Grappling with contradiction, with polarities that pull the individual in opposing ways, is actually the means by which development is promoted. If there were no crises there would be little growing experience; however, crisis out of proportion is painful and often stifling. At all stages in life we must tread the fine line between forces that can bolster and those that can break down our psychological makeup. The man in transition to middle age treads one of the finer lines in this lifelong process. Social supports in work and in family lives can help him better maintain his balance. 